\title{
GRAMMATICAL CONSTRAINTS ON INTRASENTENTIAL \\ CODE SWITCHING: EVIDENCE FROM \\ ENGLISH-AFRIKAANS CODE SWITCHING
}

\author{
Kate van Gass, Stellenbosch University
}

\section{INTRODUCTION}

Code switching is a sociolinguistic phenomenon that is found wherever two or more language varieties are used in a speech community. Bilingual or multilingual speakers who speak two or more language varieties often switch fluently between these linguistic codes, sometimes even within the same utterance, a phenomenon that is generally referred to as "intrasentential code switching"1. Various grammatical constraints on intrasentential code switching have been proposed in the literature ${ }^{2}$. In this article, I will critically examine, using EnglishAfrikaans code switching data, the empirical predictions of two of these constraints, viz. Poplack's (1980) Free Morpheme Constraint and Belazi, Rubin \& Toribio's (1994) Functional Head Constraint. I will suggest possible explanations for aspects of the data that appear to be unaccounted for in Poplack's (1980) and Belazi et al.'s (1994) frameworks. I will also characterise another approach to code switching, namely a Minimalist approach, and examine some of the advantages of such an approach by re-examining the data.

\section{THEORETICAL FRAMEWORK}

In this section I will first set out Poplack's (1980) Free Morpheme Constraint and Belazi et al's (1994) Functional Head Constraint. I will then present a short characterisation of the Minimalist Program, focusing on those aspects that are relevant to the description of code switching. 


\subsection{The Free Morpheme Constraint}

Poplack's (1980) Free Morpheme Constraint was one of the first grammatical principles to be proposed as a constraint on code switching ${ }^{3}$. Poplack (1980: 585) claims that the Free Morpheme Constraint is general enough to account for all instances of code switching and, at the same time, restrictive enough not to generate instances of non-occurring code switches. The constraint can be formulated as follows:

1. The Free Morpheme Constraint

A code switch may not occur between a bound morpheme and a lexical form unless the latter has been phonologically integrated into the language of the bound morpheme.

(Poplack 1980: 585)

According to Poplack, the Free Morpheme Constraint can account for (English-Spanish) code switching idiomatic expressions such as Cross my heart and hope to die and Si Dios quiere y la Virgen (God and the Virgin willing), as well as code switching involving set phrases (greetings, excuses) and discourse elements (for example, you know, I mean). These elements all appear to behave like bound morphemes in that they show a strong tendency to be uttered monolingually. An example of a code switch that is unacceptable in terms of the Free Morpheme Constraint is the following:

2. *Estoy eat-iendo.

am eat-ING

'I am eating.'

(MacSwan 1999: 41)

In this example, the stem eat is in English while the affix -iendo is in Spanish. According to Poplack (1980: 586), this type of item has not been attested in any study of code switching unless one of the morphemes has been integrated phonologically into the language of the other. 


\subsection{The Functional Head Constraint}

Belazi et al (1994) state that the relevant constraints on code switching should be formulated in hierarchical terms and should exploit distinctions and relations already present in the grammar. To this end, they propose the Functional Head Constraint. Belazi et al, following Chomsky (1993), assume that f-selection, a special relation between a functional head and its complement, is one member of a set of feature-checking processes. They propose that a language feature, such as [+Spanish] or [+English], is one of the relevant features checked, i.e. a functional head requires that the language feature of its complement must match its own corresponding feature. If the features do not agree, then the code switch is blocked and the utterance does not occur. This constraint is taken to be operative in all speech, although the effects of the checking of the language feature are only evident in code switching, and, in particular, in code switching between functional heads and their complements. This constraint can be formulated as follows.

\section{The Functional Head Constraint}

The language feature of the complement f-selected by a functional head, like all other relevant features, must match the corresponding feature of that functional head.

(Belazi et al 1994: 228)

According to Belazi et al (1994: 288), there is a strong relation between a functional head and its complement ${ }^{4}$. By invoking this relation, the Functional Head Constraint restricts switching between the functional head and its complement. For example, code switching is unacceptable between C and its IP complement as the Spanish-English example (4) and the Arabic-French example (5) show, while the Spanish-English example (6) shows that code switching is unacceptable between D and its NP complement.

4. *El profesor dijo que the student had received an A. 'The professor said that the student had received an A.'

5. *Le médicament que "tфła-hu:li ma hu-s\# baehi. the medicine that gave.he-it-me NEG it-NEG good 'The medicine that he gave me is not good.' 
6. ${ }^{*} \mathrm{He}$ is a demonio. ${ }^{5}$

'He is a devil.'

(Belazi et al 1994:225, 227)

Belazi et al (1994:231) claim that Poplack's (1980) Free Morpheme Constraint can be subsumed under the Functional Head Constraint if inflectional morphemes are treated as functional heads. They provide the following examples in support of this analysis. In sentence (7) the Arabic word da:r "house" cannot occur with the French plural $-s$ as switching between the French inflectional morpheme $-s$, a bound morpheme, and its head is unacceptable, and in sentence (8) the English word dance cannot occur with the Spanish $1^{\text {st }}$ person plural amos as switching between the Spanish inflectional morpheme, a bound morpheme, and its head is also unacceptable.

7. *Süuf-t da:r-s

saw-I house-PL

'I saw the houses.'

8. *We dance-amos chacha.

we dance-1pl cha-cha

'We dance cha-cha.'

(Belazi et al 1994: 231)

There are, however, serious conceptual problems with Belazi et al's approach (MacSwan 2000: 41). The Functional Head Constraint requires a language feature to check the functional head and its complement. However, this feature is not independently motivated for other linguistic phenomena and so merely appears to be a re-labelling of the descriptive facts of code switching. Features also generally have a relatively small set of discrete values, such as [ \pm past] or $[ \pm$ finite], whereas a language feature holds the possibility of extreme computational complexity (MacSwan 1999: 49). For example, how would one characterise [Greek]? If, however, the feature [+English] is regard to be a collection of the formal features which define 'English', this analysis is greatly improved. According to this view, the names of particular languages act as variables for the bundles of features which formally characterise them (MacSwan 2000: 41). 
Belazi et al also examine the constraint on switching between heads and modifiers, specifically between adjectives and the nouns they modify. According to Belazi et al (1994:232), the component languages of the code switching samples that they examined differed with respect to the placement of adjectives. From the data, it appears that code switching is possible where the placement of adjectives and nouns obey both grammars from which they are drawn, as the examples in (9) and (10) illustrate. In Tunisian Arabic, adjectives are postnominal, so in (9) mizayaena must occur postnominally, i.e. after the noun voiture. In French, nouns can receive adjectival modification to the right, so in (9) the placement of mizayaena to the right of voiture (postnominally) satisfies both grammars. In (10), the Tunisian Arabic noun karhba is satisfied by looking to the right for adjectival modification; however, the French adjective belle is a member of the set of French adjectives that occur prenominally and so this construction is ungrammatical according to the grammatical constraints of French.

9. J'ai une voiture mizayaena.

'I have a beautiful car.'

10. *and-i karhba belle.

'I have a beautiful car.'

Belazi et al (1994: 232) propose the following principle to account for the examples above.

\section{The Word-Grammar Integrity Corollary}

A word of language $\mathrm{X}$, with grammar $\mathrm{G}_{\mathrm{X}}$, must obey grammar $\mathrm{G}_{\mathrm{X}}$.

This corollary derives from the assumption, following Chomsky (1993), that all lexical entries are associated with morphological and syntactic features. According to Belazi et al (1994: 232), what is true of all lexical entries in all languages must therefore be true of code switching as well. However, there is a problem with the Word-Grammar Integrity Corollary, in that it is not a natural consequence of the Functional Head Constraint and so it would appear to be an additional code switching-specific constraint. Additional constraints, and constraints that do not exploit distinctions and relations already present in the grammar, are undesirable, as they arbitrarily limit the range of grammatical apparatus relevant to 
intrasentential code switching. Ideally all grammatical relations and operations which are relevant to monolingual language, and only these, should be relevant to bilingual language (MacSwan 2000: 43). In the following section, the Minimalist Program is briefly outlined and code switching is looked at from a Minimalist point of view.

\subsection{The Minimalist Program}

The central aim of Chomsky's (1995) Minimalist Program is the elimination of all mechanisms that are not essential or necessary on conceptual grounds alone. One way to achieve this is to restrict parameters to the lexicon, so that all linguistic variation is ascribed to the morphological properties of the lexicon (MacSwan 1999:67). In this model there are two central components: $\mathrm{C}_{\mathrm{HL}}$, a computational system for human language that is presumed to be the same in all languages, and a lexicon, which accounts for the idiosyncratic differences observed across languges (MacSwan 2000: 43).

Even phrase structure is derived from the lexical properties, as the derivation of a sentence within the Minimalist Program begins with the selection of lexical items from the lexicon. Each item consists of a set of features, which are interpreted at the two interface levels, namely PF and LF (Phonetic and Logical Form). These features are of two types: lexicalcategorical (LC) features and functional (F) features. LC-features consist of semantic features, categorical features like $[ \pm$ nominal $]$ and $[ \pm$ verbal], and phonological features. F-features relate to morphological properties such as tense, case, and agreement. Lexical items are projected and merged with one another through the generalised transformation (GT), the only structure-building mechanism in the Minimalist Program. These items are subsequently licensed for interpretation at the PF and LF levels.

In order to license a lexical category, its F-features are moved into positions where they can be checked against the corresponding features of a functional category. The F-features of functional categories are of two types: V-features, which agree with the corresponding features of a lexical head; and $\mathrm{N}$-features, which agree with the corresponding features associated with phrases. V-features are checked in head-head configurations and $\mathrm{N}$-features in Spec-head configurations. The F-features of a functional head may either be strong or weak. 
Strong features must be checked in the overt syntax, before Spell-Out, or the derivation will crash at PF. Weak features however need only be checked after Spell Out in the covert syntax, as they are not visible at PF. The organisation of the grammar is represented schematically below:

Figure 1: The Minimalist Grammar

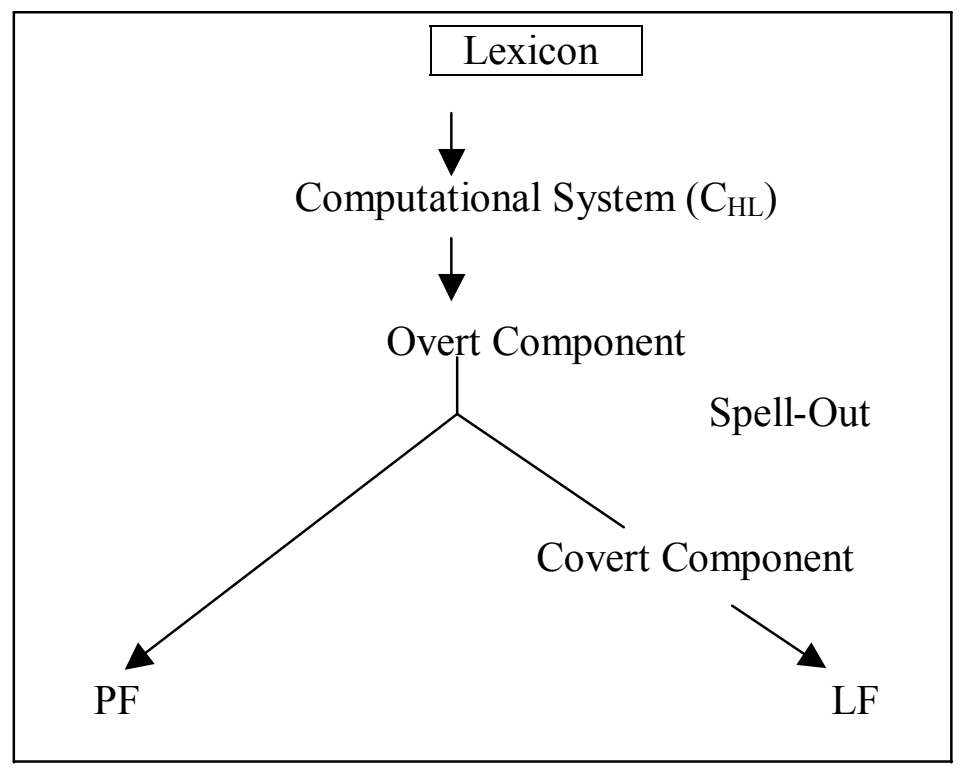

In order for a derivation to be phonetically realised at PF, it is necessary for the F-features of a lexical head to be combined with the LC-features within a categorical head. For example, suppose the F-features of a lexical head $\mathrm{Y}$ are adjoined to a functional head $\mathrm{X}$ to form the morphosyntactic complex $X^{\prime}$, but $X^{\prime}$ does not contain any LC-features, then $X^{\prime}$ will not be a legitimate PF-object and the derivation will crash. In this case either (i) $\mathrm{X}^{\prime}$ can be adjoined by Move-F to a functional head $\mathrm{Z}$ higher up in the structure (one which does contain LCfeatures) to form Z', an interpretable PF-object, or (ii) the LC-features of the lexical head Y can move overtly by Move-LC to X' to form a legitimate PF-object (Oosthuizen 1998: 65-66).

A Minimalist approach to code switching must explain the code switching facts within the general framework of Chomsky (1995) as outlined above and must incorporate the minimal theoretical assumptions to account for the code switching data. MacSwan (1999 \& 2000) adopts such an approach to code switching, one that assumes the minimal code switchingspecific apparatus. He states his research agenda as follows: 
12. Nothing constrains code switching apart from the requirements of the mixed grammars.

(MacSwan 1999: 146)

MacSwan's (1999:146) assumption in (12) entails, firstly, that no principle of grammar be explicitly formulated for code switching, as in Poplack's (1980) approach that suggests that code switching is constrained by a sort of "third grammar" (MacSwan 2000: 38); and, secondly, that the identities of particular languages are ignored for the purposes of linguistic theory. Instead, the language-particular requirements of code switching are assumed to be represented in morphology, i.e. in the lexicon. This immediately overcomes one of the objections that Belazi et al's (1994) proposal faces, namely that the language feature that they propose is not independently motivated for other linguistic phenomena. In a Minimalist explanation of the acceptability of code switched sentences, there is an appeal to morphologically sensitive mechanisms motivated to account for grammaticality in monolingual sentences (MacSwan 1999:147).

MacSwan's (1999) Minimalist approach to code switching assumes that the computational system is invariant across all languages and that parameters are part of the lexicon, which the computational system uses to build larger structures. Each lexical item introduces grammatical features, or F-features, into the derivation, which must be checked. According to MacSwan (1999: 148), the language faculty does not have to pay attention to the sociopolitical identity of words (for example, our associations of window with "English", and of venster with "Afrikaans"). The language faculty is only sensitive to the fact that these lexical items have features which enter into the derivation and that these features must be checked. When features mismatch or when uninterpretable features cannot be checked, the derivation crashes, whether the set of lexical items is associated with one specific language or two (or more). The acceptability of a linguistic expression depends on whether its features match, no matter whether it is a monolingual or a code switched expression.

If all syntactic variation is associated with the lexicon, as in the Minimalist Program, then code switching can be seen as the result of mixing two lexicons in the course of a derivation (MacSwan 2000: 45). There is no need for specific grammatical constraints to mediate the 
contradictory requirements of both languages. Instead a Minimalist approach sees the grammar used for code switching as a combination of both lexicons and the invariant computational system $\left(\mathrm{C}_{\mathrm{HL}}\right)$.

MacSwan (2000: 45) notes, however, that Chomsky (1995) and others have pointed out that the mapping to phonetic form is completely different from the syntactic component of the grammar. Syntactic operations (GT's) apply at any time and in any order, while PF component operations must apply in a particular order. Therefore, if the two PF components are mixed in the same way as the two lexicons for mixing in the syntactic component, the ordering of rules will not be preserved. Rather than invoke a constraint which would allow the two systems to interface, MacSwan (2000: 45) proposes the hypothesis that code switching is impossible at PF, expressed below:

13. PF Disjunction Theorem

(i) The PF component consists of rules/constraints which must be (partially) ordered/ranked with respect to each other, and these orders/ rankings vary cross-linguistically.

(ii) Code switching entails the union of at least two (lexically encoded) grammars.

(iii) Ordering relations are not preserved under union.

(iv) Therefore, code switching within a PF component is not possible.

(MacSwan 2000: 45)

According to MacSwan (2000: 46), code switching at PF generates "unpronounceable" elements because phonological systems cannot be mixed. The PF Disjunction theorem does not function as a grammatical constraint on code switching, rather it is a theory about the relationship between the PF components of a bilingual's linguistic system and is deduced from the nature of phonetic rules. MacSwan (2000: 50) states, "the supposition that there are no code switching-specific constraints can lead to new insights both in bilingualism and in the theory of grammar generally". In the analysis of the English-Afrikaans code switching data that follows, a Minimalist approach will be used to account for aspects of the data unaccounted for in Poplack's (1981) and Belazi et al's (1994) frameworks, and some of the advantages of a Minimalist approach will be demonstrated. 


\section{THE DATA}

South Africa is a multilingual country; however, the majority of white South Africans can only speak English and/or Afrikaans. In this article I will look at code switching between English and Afrikaans, as this is an everyday phenomena. Code switching has a highly individual nature, as Lipski states, "the role of individual idiosyncratic factors seems to be an important aspect of code switching in that among groups of approximately equal bilingual abilities some code switch more than others" (in MacSwan 1999: 39). Because of this, I have collected data from one Afrikaans-English bilingual. Ferdinand, aged 26, is from Paarl in the Western Cape Province of South Africa, a predominantly Afrikaans speaking town, and was, at the time of data collection, a contestant on the South African version of the television show Big Brother.

Big Brother is a reality television show where 12 contestants spend up to 106 days in a purpose-built house in order to win a million Rand. While in the house, the housemates have no contact with the outside world and they are under 24-hour camera surveillance. There is no place in the house, or the garden attached to it, where the housemates cannot be seen or heard by "Big Brother", the entity in charge of the show. Once a day, each housemate is required to go into a special room, the "Diary Room", to have a conversation with "Big Brother" and discuss their thoughts and feelings. Once every two weeks two housemates are nominated by their fellow housemates and then one housemate is voted off the show by the viewing public. Because of the format of the show, the housemates seem to soon forget that they are on camera and their conversations seem natural and informal.

One major concern of sociolinguistic research is the manner in which data are collected, with the ideal being that all data should come from "natural" conditions. A major problem with data collection is the Observer's Paradox (Labov 1972: 209). According to Labov (1972: 209), the aim of linguistic research is to observe the way that people use language when they are not being systematically observed; yet these data can only be obtained by systematic observation. By taping the conversations between Ferdinand and the other housemates, I was able to gather data as an observer, not a participant, without the participants themselves being aware of my 
observation of their language use: the housemates knew that they were being observed, but they were not aware that they were being observed by anyone for purposes other than entertainment, general interest, or common curiosity. In this way, I overcame to a large extent the Observer's Paradox. MacSwan (1999: 102), however, argues that although naturalistic data are useful for obtaining initial findings in a natural setting, they do not tell us what cannot occur, and so are of limited use in constructing a theory. However, for this article, in which I examine the merit of two proposed linguistic constraints on code switching, the naturalistic data will be assumed to be sufficient.

\section{THE ANALYSIS}

Below I present an analysis of the code switching data obtained from the Big Brother show. A list of all the code switching utterances collected is given in the Appendix. In this section, I will evaluate the empirical predictions of Poplack's (1981) Free Morpheme Constraint and Belazi et al's (1994) Functional Head Constraint against the data and I will suggest possible explanations for cases where these constraints do not account for the data.

I will begin by examining the problematic aspects of the data. In the utterances collected, there are four examples of Afrikaans words with English inflectional morphology.

$\begin{array}{ll}\text { 14. } \text { klapped } & \text { HIT - past } \\ \text { 14. vloeking } & \text { SWEARING } \\ \text { 15. dopping } & \text { DRINKING } \\ \text { 16. gooiing } & \text { THROWING }\end{array}$

These examples appear to contradict Poplack's (1981) Free Morpheme Constraint which prohibits switching between a bound morpheme and a lexical form. This constraint appears to hold even within a Minimalist analysis. According to MacSwan (2000: 46), the PF Disjunction Theorem predicts that code switching below X (head level) is not permitted, since $\mathrm{X}$ 's are inputs to PF. However, it could be argued that these are examples of Afrikaans words borrowed into the English lexicon where they have received the inflectional morphemes. Cases of borrowing occur when a new stem is introduced into a specific lexicon where rules 
of word formation, internal to that lexicon, add appropriate feature-bearing inflectional morphology before the item enters the derivation, where feature checking begins (MacSwan 2000:46). On such an analysis, the data would then provide support for Poplack's (1981) original Free Morpheme Constraint, as there are no switches between a bound morpheme and its root. This conclusion is similar to the one that MacSwan (1999) reaches in his analysis of his Spanish-Nahuatl data. He states, "with respect to morphological switches, then, it appears that Poplack's constraint is essentially correct as a descriptive generalisation" (MacSwan 1999: 224).

When evaluating Belazi et al's (1994) Functional Head Constraint against the data collected, we again encounter a problem. There are many examples of apparent switches between a determiner and its NP complement. These would then be clear instances of switching between functional heads and their complements, switches that are ruled out by the Functional Head Constraint. Consider, for example, the following expressions:

17. that kameratjie
$\begin{array}{ll}\text { 18. the kop } & \text { that LITTLE CAMERA } \\ \text { 19. the Oranjerivier } & \text { the ORANGE RIVER } \\ \text { 20. some emmers } & \text { Some BUCKETS } \\ \text { 21. this tongetjie } & \text { this LITTLE TONGUE } \\ \text { 22. this boesman } & \text { this BUSHMAN }\end{array}$

Note that each NP in these expressions consists of a single word. It is possible, therefore, that these expressions are, as in the case of (14)-(16), examples of Afrikaans words borrowed into the English lexicon. One could speculate that if the speaker used both the Afrikaans word and the corresponding English word, then it would have to be analysed as an instance of code switching. However, no examples of this kind were found in the data and so the tentative conclusion is that the Afrikaans word replaces the English word in the observed speaker's lexicon. This would provide supporting evidence for Belazi et al's (1994) Functional Head Constraint, as expressions like (17)-(22) would then not be examples of switches between determiners (functional heads) and their complements. 
A similar analysis can be made of the following example:

23. You will lag with every fact you get, but you will get it.

LAUGH

In this case will, the auxiliary verb, is a functional head and its complement, the verb lag, has been switched. This would be contrary to the predictions made by Belazi et al's (1994) Functional Head Constraint. Once again, however, it seems more likely that the verb lag is itself also a borrowing in the observed speaker's lexcion. This would then entail no violation of the Functional Head Constraint.

The above analyses of the problematic aspects of the data highlight a phenomenon that seems to be closely related to code switching and that should be examined in more detail, namely borrowing. Traditionally, "borrowing" is defined as the phonological, morphological and syntactic adaptation of a foreign word or short expression into the language being spoken (Grosjean 1982: 308). It does not have the conversational or interactional functions of intrasentential code switching ${ }^{6}$, and is usually, but not necessarily, motivated by lexical need. Established borrowings typically show full linguistic integration, native-language synonym replacement, and widespread diffusion, even among host language monolinguals (Poplack \& Meechan 1995: 200).

The borrowing that is evidenced in the data seems to be a different type of borrowing to the traditional borrowing. Whereas borrowing in the traditional sense can almost be seen as "fossilised", where a borrowed word from one lexicon has become a permanent part of the speaker's other lexicon, the borrowing that takes place in the data is a more immediate and temporary phenomenon. It appears to be a type of on-line borrowing, where a word from one lexicon is borrowed into the speaker's other lexicon only for the duration of the utterance or the conversation ${ }^{7}$. This phenomenon then displays many of the characteristics of intrasentential code switching but does not seem to be subject to the syntactic constraints on code switching. This type of borrowing is referred to as "nonce" borrowing ${ }^{8}$. Nonce borrowings differ from established borrowings in that they are not necessarily recurrent, widespread, or recognised by host language monolinguals. 
Samar \& Meechan (1998: 204) point out that, due to variation in phonological, and even morphological, integration, it is difficult to distinguish between intrasentential code switching and borrowing, as they may appear similar on the surface. The most important characteristic of borrowings seems to be that they are at least morphologically and syntactically integrated into the host language. Another characteristic of borrowing is that generally only content words are borrowed. According to Sankoff, Poplack \& Vanniarajan (1990), in most studies borrowings consist "primarily of nouns, with many adjectives and verbs, and a number of adverbs. Pronouns are very seldom borrowed nor are articles, quantifiers, demonstratives, and prepositions". These characteristics appear to be applicable to the utterances in (14)-(23), and so the suggested analysis of these utterances as nonce borrowings rather than intrasentential code switches appears to be consistent.

Another issue that the data raises is the status of conjunctions. This is an area of syntax that is not very well understood. In the data, there are examples of switching between a conjunction and the phrase that follows it, as the following examples show.

24. Lekker Hanepoot, and jou gat brand because later on you can't... NICE HANEPOOT YOUR BOTTOM BURNS

25. You mustn't come and say you want to have a drink with me and kom fokken vreet en fokkol drink nie. COME FUCKING EAT AND FUCK ALL DRINK NEG

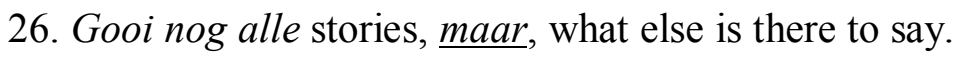
"TELL MORE" BUT

If conjunctions are lexical heads, then there are no problems with these examples: they would be simple examples of code switching between a lexical head and its complement. However, if the conjunctions are analysed as functional heads, (24)-(26) represent potential counterexamples to Belazi et al's (1994) Functional Head Constraint, as they are examples of switching between a functional head (the conjunction) and its complement (the following clause). 
One test of whether words have descriptive content, that is, whether they represent lexical heads, is to see whether they have antonyms. If a word has an antonym, then it is a lexical item, not a functional item (Radford 1997: 45). Conjunctions have no obvious antonyms; for example, there is no opposite for and or but. This suggests that conjunctions lack lexical content and should be analysed as functional items. If conjunctions represent functional items, and despite this are able to be switched, then it is also possible to make a prediction as regards complementisers, which are functional items similar in nature to conjunctions ${ }^{9}$. There are no examples of switched complementisers in the data but a possible prediction, in line with the evidence from the conjunctions, is that switching could occur between a complementiser and its complement as the following (generated) example shows ${ }^{10}$.

27. Who told you that ek sal saamgaan.

I WILL GO WITH

It would seem that Belazi et al's Functional Head Constraint needs to be modified in the light of this data. One proposal could be that a distinction be made between functional heads with lexical complements and functional heads with functional complements. For example, determiners and auxiliary verbs are functional heads with lexical complements. Therefore if all instances of possible switches between determiners/auxiliary verbs and their complements are analysed as instances of nonce borrowing, then the data in this study would confirm that switching between these items is unacceptable ${ }^{11}$. However, conjunctions and complementisers are functional heads with functional complements and the prediction is that switching between these items should be possible. It may be necessary, therefore, to modify Belazi et al's Functional Head Constraint to exclude functional heads that have functional complements from this constraint and so allow switching between these items to take place.

In a Minimalist approach to code switching, all cross-linguistic variation is lexically encoded and the syntactic operations of the computational system are assumed to be invariant. Code switched items are selected from one lexicon and introduced into the derivation containing elements from the other lexicon, where they are checked for convergence. No specific research has been done on code switched conjunctions. so we can only speculate that in the 
case of these examples the features of the code switched conjunctions are checked (they do not mismatch) and therefore the derivation is acceptable.

If we examine other types of code switching utterances in the data, we see that switching between verbs and their complements is present, for example:

28. They [vP are [DP fokken vaaljaapies sommer].]

FUCKING CHEAP WINES JUST

"just fucking cheap wines"

29. That one [vp moves [DP sy gat af] in this room.]

ITS BOTTOM OFF

Switching also takes place between a verb and its specifier, the subject DP, for example:

30. [vp [Spec Ou boesmanseuntjie] [v' is saying hello to you all].] OLD BUSHMAN SON

All these examples are consistent with Poplack's (1981) Free Morpheme Constraint and Belazi et al's (1994) Functional Head Constraint as they are evidence of switching between lexical heads and their complements or specifiers. In terms of a Minimalist approach to code switching, these examples would be analysed without resorting to code switching-specific constraints. They are simply instances of acceptable code switches.

As can be seen from the above analysis, one advantage of a Minimalist approach is that, because linguistic differences are encoded in particular lexical items, the grammatical contribution of each language in a code switched sentence can be clearly identified. Another advantage is that, because the syntactic component of the computational system $\left(\mathrm{C}_{\mathrm{HL}}\right)$ may be assumed to be invariant cross-linguistically, no "control structure" or "third grammar" is required to mediate between contradictory requirements (MacSwan 2000: 50). The analysis of (14)-(16) highlights a further advantage of a Minimalist approach, namely that, because the phonological component of the computational system $\left(\mathrm{C}_{\mathrm{HL}}\right)$ is assumed to be different in nature from the syntactic component, and because rules/constraints of the phonological 
system are ordered/ranked with respect to each other, we may disallow code switching in phonology but still permit it in syntax in a natural way.

\section{CONCLUSION}

In this article, I have examined the sociolinguistic phenomenon of intrasentential code switching. I critically examined the empirical predictions of two of the syntactic constraints proposed for code switching, Poplack's (1981) Free Morpheme Constraint and Belazi et al's (1994) Functional Head Constraint, against the English-Afrikaans code switching data collected. I also suggested possible explanations for aspects of the data unaccounted for by Poplack (1981) and Belazi et al (1994). My findings indicate that Poplack's Free Morpheme Constraint is supported by the code switching data. However, it is suggested that Belazi et al's Functional Head Constraint be modified in order to account for aspects of the data that do not correspond to the empirical predictions of this constraint, specifically the switching of conjunctions. However, if a Minimalist approach is followed, then the aim is to eliminate all code switching-specific constraints and neither Poplack's (1981) approach nor that of Belazi et al's (1994) remains relevant. In my analysis, some of the advantages of a Minimalist approach were noted. Further advantages are, firstly, that because the Minimalist Program is motivated by many theoretical and empirical considerations in the context of monolingual data (Chomsky, 1995), pursuing a Minimalist approach to code switching allows one to remain consistent with current work in syntactic theory as it relates to monolingual language, and, secondly, that because Minimalism focuses on minimal use of theoretical assumptions (allowing only those suppositions which correspond to "virtual conceptual necessity"), it is a natural framework in which to take seriously the view that there are no code switchingspecific constraints. This forces one to examine the data more rigorously, and may often lead to new insights in bilingualism and the theory of grammar (MacSwan 2000: 50). One area that evidently requires further research is the status of conjunctions, and possibly complementizers. Another area for further examination is the distinction between borrowing and nonce borrowing, and finally, if deemed necessary, an examination of the proposed modification to Belazi et al's Functional Head Constraint would determine whether in fact this modification is borne out by the data. 


\section{NOTES}

${ }^{1} \mathrm{Cf}$. (Van Dulm, this issue)

${ }^{2}$ Cf. (MacSwan 1999), (Belazi, Rubin \& Toribio 1994), (Di Sciullo, Muysken \& Singh 1986), (Joshi 1985), and (Poplack 1980).

${ }^{3}$ For a critical examination of Poplack's (1980) second constraint, the Equivalence Constraint, see (MacSwan 1999), (Belazi, Rubin \& Toribio 1994), (Di Scullio, Muysken \& Singh 1986) and (Berk-Seligson 1986).

${ }^{4}$ Belazi et al (1994) do not spell out what this strong relation is, but it can be assumed to be the co-dependance of these two elements. No checking can take place without a functional head and, similarly, no checking takes place if there is nothing to check.

${ }^{5}$ If the Spanish word demonio in example (6) was phonologically adapted to English then it would be analysed as a borrowing and the example would be acceptable. The distiction between borrowing and code switching will be examined in a later section in this article.

6 According to Gumperz (1982 in MacSwan 1999:37) code switching can broadly be described in terms of three social and pragmatic properties: situational, metaphorical and conversational. Borrowing, by contrast, is merely a characteristic of language contact, which does not have these properties.

${ }^{7}$ In a Minimalist approach, this entails the introduction of a new stem into a specific lexicon where morphologically complex items are formed before entering the derivation, where feature checking begins (MacSwan 2000: 46).

${ }^{8}$ Cf. (Weinreich 1963); (Poplack, Sankoff \& Miller 1988); (Poplack, Wheeler \& Westwood 1989); (Sankoff, Poplack \& Vanniarajan 1990); (Poplack \& Meechan 1995: 200); and (Grosjean 1995: 263).

${ }^{9}$ In traditional grammar, complementisers like that/for/if are categorised as (one particular type of) subordinating conjunctions (Radford 1997: 500).

${ }^{10}$ This example was generated by Van Dulm (this issue).

${ }^{11}$ See examples (17)-(23) 


\section{REFERENCES}

Belazi, H.M., E.J. Rubin and A.J. Toribio. 1994. Code switching and X-bar theory: The Functional Head Constraint. Linguistic Inquiry 25(2): 221-237.

Berk-Seligson, S. 1986. Linguistic constraints on intrasentential code-switching: a study of Spanish-Hebrew bilingualism. Language in Society 15: 313-348.

Chomsky, N. 1995. The Minimalist Program. Cambridge, Mass.: MIT Press.

Di Sciullo, A.M., P. Muysken and R. Singh. 1986. Government and code-mixing. Journal of Linguistics 22: 1-24.

Grosjean, F. 1982. Life with two languages: an introduction to bilingualism. Cambridge: Cambridge University Press.

Grosjean, F. 1995. A psycholinguistic approach to code-switching: the recognition of guest words by bilinguals. In Milroy and Muysken (eds.). 1995: 259-275.

Joshi, A. 1985. Processing of sentences with intrasentential code switching. In D.R. Dowty, L. Kattunen and A.M. Zwicky (eds.). Natural language parsing: psychological, computational and theoretical perspectives. New Jersey: Lawrence Erlbaum.

Labov, W. 1972. Sociolinguistic Patterns. Philadelphia: University of Pennsylvania Press.

MacSwan, J. 1999. A minimalist approach to intrasentential code switching. New York: Garland Publishing.

MacSwan, J. 2000. The architecture of the bilingual language faculty: evidence from intrasentential code switching. Bilingualism: Language and Cognition 3: 37-54.

Milroy, L. and P. Muysken (eds.). 1995. One speaker, two languages. Cambridge: Cambridge University Press.

Oosthuizen, J. 1998. The final NIE in Afrikaans Negative Sentences. SPIL 31: 61-93. Department of General Linguistics, University of Stellenbosch.

Poplack, S. 1980. Sometimes I'll start a sentence in English y termino en Espanol: toward a typology of code-switching. Linguistics 18: 581-618.

Poplack, S., D. Sankoff and C. Miller. 1988. The social correlates and linguistic processes of lexical borrowing and assimilation. Linguistics 26: 47-104.

Poplack, S., S. Wheeler and A. Westwood. 1989. Distinguishing language contact phenomena: evidence from Finnish-English bilingualism. In K. Hyltenstam and L.K. 
Obler (eds.). 1989. Bilingualism across the lifespan. Cambridge: Cambridge University Press.

Poplack, S., and M. Meechan. 1995. Patterns of language mixture: nominal structures in Wolof-French and Fongbe-French bilingual discourse. In Milroy and Muysken (eds.). 1995: 199-232.

Radford, A. 1997. Syntactic theory and the structure of English. A minimalist approach. Cambridge: Cambridge University Press.

Samar, R.G. and M. Meechan. 1998. The null theory of code-switching versus the nonce borrowing hypothesis: testing the fit in Persian-English bilingual discourse. The International Journal of Bilingualism 2: 203-219.

Sankoff, S. Poplack and S. Vanniarajan. 1990. The case of the nonce loan in Tamil. Language Variation and Change 2: 71-101. 


\section{APPENDIX}

1. He supports me nogal heavy.

\section{RATHER}

2. I've sommer klapped a lot of people in one night.

JUST HIT

3. I'm vloeking the wet wood all night.

SWEARING (AT)

4. Same as last night, ek belowe jou.

I PROMISE YOU

5. Lekker Hanepoot, and jou gat brand because later on you can't... NICE HANEPOOT YOUR BOTTOM BURNS

6. It's just pure doppe.

DRINKS/SHOTS

7. But they donner af there.

CRASH DOWN

8. They are fokken vaaljaapies sommer.

FUCKING CHEAP WINES JUST

9. We take a nice plastic bag, we trap the juice out of the grapes.

STEP

10. I can show... you how to make a ('n) mos.

$$
\operatorname{MUST}(=" \text { new wine") }
$$

11. You will lag with every fact you get, but you will get it.

LAUGH

12. Riaad, jou gaan ek gesuip maak brother.

YOU WILL I DRUNK MAKE

13. There's one thing, you're gonna be fokken very fit at the end of the evening.

FUCKING

14. The two times in my life I've broken a record I was lekker vlamgat.

NICELY DRUNK

15. Everything looks sommer lekker here.

$$
\text { JUST NICE }
$$


16. That chicken was actually kwaai huh.

FIERCE

17. You mustn't come and say you want to have a drink with me and kom fokken vreet en fokkol drink nie.

COME FUCKING EAT AND FUCK ALL DRINK NEG

18. Here that Ferdinand is mal gesuip and look how he's still driving home. Meantime LORD MAD DRUNK

he's mal sober.

MAD

19. But tell me that one's sommer in die groove nou weer.

$$
\text { JUST IN THE AGAIN }
$$

20. I'm like that, somedays cold and bedonderd as hell.

$$
\text { MOODY }
$$

21. She's got sommer bitter-lekker lips.

$$
\text { JUST VERY NICE }
$$

22. Then you must know you're getting a bit bedonderd in the kop.

$$
\text { CRAZY HEAD }
$$

23. I scheme we must klap this whole move here.

HIT

24. You two gooi mekaar, lappe-lappe, slap-slap, lippe teen die klippe.

"GO AT IT" LIPS AGAINST THE ROCKS

25. That one moves sy gat af in this room.

ITS BOTTOM OFF

26. That kameratjie, that larnie can't leave me alone.

LITTLE CAMERA

27. Gooi nog alle stories, maar, what else is there to say.

"TELL MORE" BUT

28. I think of Mafias, they donder you up six love.

BEAT

29. I was getting gou befok in that room.

QUICKLY "ANGRY" 
30. How to put Ferdinand aan, gee hom...

ON GIVE HIM

31. When I was that age I was just dopping it.

DRINKING

32. This is bedonderd long.

"VERY"

33. And everybody lag $a f$.

LAUGHS

34. I would frikken lag myself moer toe if its every night ten, eleven o'clock.

$$
\text { LAUGH "MOTHERLESS" }
$$

35. My plans are not working lekker.

WELL

36. I sommer talk to him.

JUST

37. Like sommer lekker blue.

$$
\text { JUST NICE }
$$

38. No man, natuurlik, then they kak.

$$
\text { NATURALLY SHIT }
$$

39. Upington se mense go with the Oranjerivier to Namibia.

'S PEOPLE ORANGE RIVER

40. I want to do a bit of gym still, lift up some emmers.

BUCKETS

41. This tongetjie of yours in the back's kind of getting affected by it.

LITTLE TONGUE

42. Ou boesman seuntjie is saying hello to you all. OLD BUSHMAN SON

43. They all come and sit here now and read their books just to listen what this boesman is gooiing out. BUSHMAN THROWING

44. I've got for you, not kiste vol, but tonne wine vat barrels full of stuff.

$$
\text { CHESTS FULL TONS(OF) }
$$

